\title{
UFPR HÍBRIDA: IMPLEMENTANDO AÇÕES PARA CONSECUÇÃO DA EDUCAÇÃO HÍBRIDA
}

\author{
CURITIBA/PR JULHO/2018
}

\author{
ANNA JUNGBLUTH - UFPR - annajungbluth@gmail.com \\ MARINA LUPEPSO - UFPR - marininha.lup@gmail.com \\ NATHALIA SAVIONE MACHADO - UFPR - nathcipead@gmail.com
}

Tipo: Relato de Experiência Inovadora (EI)

Categoria: Métodos e Tecnologias

Setor Educacional: EDUCAÇÃO SUPERIOR

\begin{abstract}
RESUMO
A Educação Híbrida integra experiências formativas online e presencial para proporcionar um ensino personalizado. Pautado nessa concepção, foi criado em 2017, na Universidade Federal do Paraná, o Projeto UFPR HÍBRIDA. O presente trabalho busca descrever as ações e os resultados desse projeto por meio de uma abordagem qualitativa da prática pedagógica utilizando como instrumentos de coleta de dados os seguintes artefatos: planilhas de cursos com adesão à UFPR HÍBRIDA, site do projeto e registros jornalísticos. São perceptíveis os avanços desde o lançamento da resolução institucional em 2010, com um significativo número de cursos presenciais que inserem carga horária a distância. $O$ Projeto UFPR HÍBRIDA tem se tornado cada vez mais aberto e colaborativo, com ações representadas por oferta de cursos de formação técnico-pedagógicas e por vivências formativas para a educação híbrida. Observamos contudo, que seu fortalecimento depende do desenvolvimento de instrumentos de avaliação, de plataformas adaptativas que aprimorem o princípio da personalização, além de maior apoio político e de financiamento que sustentem as práticas educacionais híbridas.
\end{abstract}

Palavras-chave: Educação híbrida. UFPR HÍBRIDA. Inovação na EaD. 


\section{Introdução}

Uma das tendências da educação superior a curto prazo, de acordo com o Horizon Report (JOHNSON et al, 2016) é a utilização da mediação da aprendizagem e da aprendizagem híbrida. Segundo Johnson et al (2016), as abordagens híbridas apresentam potencial para promover a aprendizagem independente e a colaboração, como também fornecer mais canais de comunicação entre estudantes e professores.

Nessa perspectiva, Johnson et al (2016) apresentam os resultados de alguns estudos a respeito do ensino híbrido na educação superior. Um dos exemplos citados pelos autores foi um estudo que buscou analisar o desempenho dos discentes em uma aula de química da Universidade de Massachusetts. Constataram que a estrutura híbrida levou a um maior envolvimento com o material do curso, promoveu a aprendizagem mais ativa, como também melhorou o sucesso dos estudantes (aumento de quase 12\% nas notas dos exames) quando comparado aos do ensino totalmente presencial.

No Brasil a portaria no 2.253 de 18 de outubro de 2001 possibilitou a inclusão de atividades não presenciais em até $20 \%$ da carga horária do curso, o que acabou por contribuir com a adoção de uma abordagem híbrida no ensino superior (TORI, 2009, p. 121, 122). No âmbito da Universidade Federal do Paraná (UFPR) foi instituída em 2010 a Resolução n 72/10 - CEPE (UFPR, 2010) para regulamentar a oferta de disciplinas da modalidade a distância nos cursos de graduação e educação profissional e tecnológica presenciais.

Permeada por essas tendências e tendo em vista um histórico de ações e legislações, a UFPR por meio da Coordenação de Políticas de Educação a Distância (CIPEAD) criou em 2017 o projeto UFPR HÍBRIDA com o objetivo de oferecer apoio aos cursos de graduação da instituição no que diz respeito à formação dos docentes, ao planejamento, implantação e efetivação da educação híbrida.

O presente relato de experiência busca descrever as ações e os resultados do projeto UFPR Híbrida nos anos de 2017 e início de 2018. Para isso apresentamos o referencial teórico que sustenta o conceito e os pressupostos da educação híbrida, os procedimentos metodológicos para a coleta de dados, a apresentação e discussão dos principais resultados do projeto contendo as estatísticas de cursos híbridos na universidade, o site criado para compartilhamento e orientações sobre a educação híbrida como também os processos formativos ofertados aos professores que ministram ou têm interesse em ofertar disciplinas híbridas na graduação e à comunidade acadêmica em geral. 


\section{Referencial teórico}

A educação híbrida insere o estudante no centro do processo de aprendizagem e conecta as modalidades de educação presencial e a distância de uma forma integrada, buscando o que seria o melhor destes dois mundos e visando a personalização do ensino (CHRISTENSEN; HORN; STAKER, 2013; PERES; PIMENTA, 2011; BACICH, s/d; MACHADO; LUPEPSO; JUNGBLUTH, 2017). Essa articulação compreende que pelo menos parte do ensino ocorre de forma online possibilitando ao estudante gerenciar seu tempo, local e ritmo de aprendizagem. Também prevê que uma parte do ensino que ocorra em uma localidade física supervisionada, por exemplo uma sala de aula, para que o estudante possa aprender com apoio da mediação presencial de um professor (HORN; STAKER, 2015; MACHADO; LUPEPSO; JUNGBLUTH, 2017).

Figura 1 - Conceito de Educação Híbrida - um programa de educação formal no qual o estudante aprende:

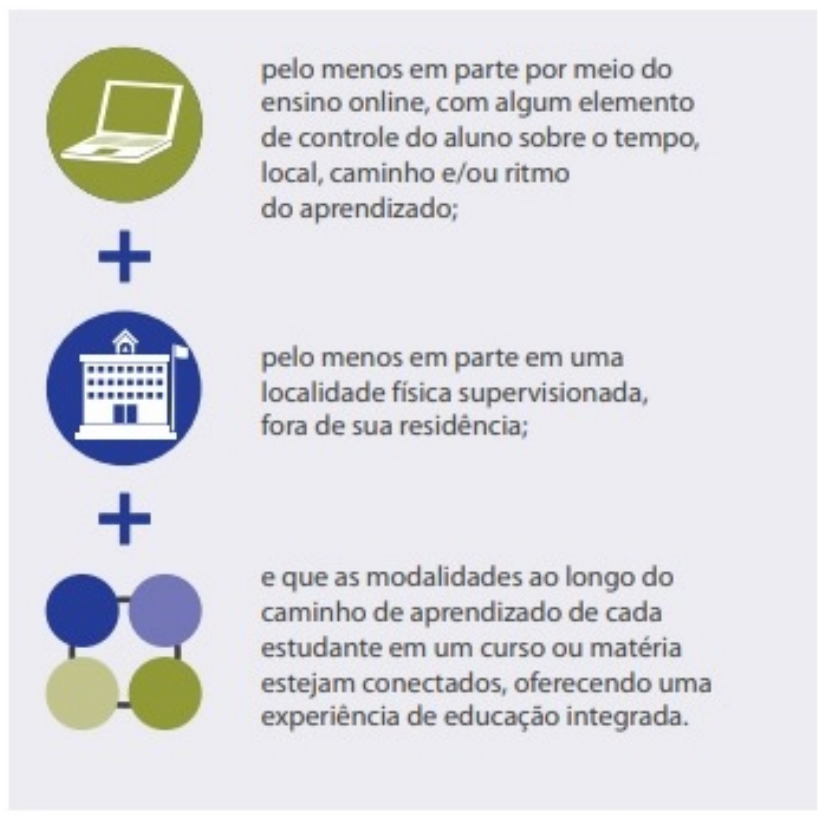

Fonte: Christensen, Horn e Staker (2013, p. 8).

Ao fornecer experiências de aprendizagem de forma integrada, combinando o ensino online e o ensino presencial, a Educação Híbrida também passa a inserir as tecnologias de informação e comunicação - TICs que, junto com outras tecnologias (digitais, emergentes) são consideradas potencializadoras para o ensino e a aprendizagem (BACICH; TANZI NETO; TREVISANI, 2015).

Utilizar um ambiente virtual de aprendizagem - AVA é uma das tecnologias que apoiam a prática da Educação Híbrida no sentido de flexibilizar tempo, espaço e ritmo do 
estudante, sendo possível disponibilizar disciplinas e materiais, criar atividades e promover a interação entre estudantes e educadores em uma mesma "sala de aula virtual" (MACHADO; LUPEPSO; JUNGBLUTH, 2017).

Gomes e Serrano (2014) apontam que a inovação educativa depende, entre outros fatores, de que educadores estejam atentos às tecnologias emergentes. Para se praticar a ideia da Educação Híbrida, tendo em vista que envolve elementos inovadores, é necessário que as possibilidades tecnológicas, os artefatos, as ferramentas e os recursos digitais (inclusive os recursos educacionais abertos) sejam conhecidos e façam parte do repertório de educadores e estudantes. Este conhecimento envolverá uma maior compreensão, por exemplo, dos "potenciais de interatividade" das tecnologias para o desenho das propostas educacionais (TORI, 2009, p. 126).

O preceito de Educação Híbrida é mais amplo, pois não só incorpora as potencialidades de diferentes tecnologias e artefatos para uma experiência de formação integrada, como também apresenta estratégias e métodos que visem estimular 0 aprendizado (MACHADO; LUPEPSO; JUNGBLUTH, 2017), sejam por meio de abordagens inovadoras e metodologias ativas para a aprendizagem, os modelos de sala de aula invertida ou de rotação por estações, entre outras possibilidades (HORN; STAKER, 2015; MACHADO; LUPEPSO; JUNGBLUTH, 2017).

\section{Procedimentos metodológicos}

Este relato de experiência se caracteriza como pesquisa qualitativa da prática pedagógica pautada no envolvimento com a pesquisa pedagógica que possa contribuir para a melhoria do processo de ensino e aprendizagem. Esse tipo de pesquisa se fundamenta no envolvimento do pesquisador da área de educação e seu aprimoramento profissional (LANKSHEAR; KNOBEL, 2008).

O contexto do estudo originou a partir do trabalho pedagógico realizado pelas autoras da presente pesquisa em seu campo direto de atuação: a Universidade Federal do Paraná (UFPR). Oficializando as ações já realizadas desde 2010, no ano de 2017, a Coordenação de integração de Políticas de Educação a Distância da UFPR lançou o projeto UFPR HÍBRIDA com o objetivo de consolidar o apoio aos cursos e aos professores que desejam inserir o uso de tecnologias e de outros ambientes de aprendizagem além do espaço físico tradicional da sala de aula. $O$ projeto também oferta cursos de formação e vivências formativas para a comunidade acadêmica auxiliando no uso do ambiente virtual de aprendizagem (AVA) e na aplicação de metodologias ativas que contribuam para a efetivação da educação híbrida. 
Figura 2 - Fluxo formativo para a implementação da Educação Híbrida na UFPR

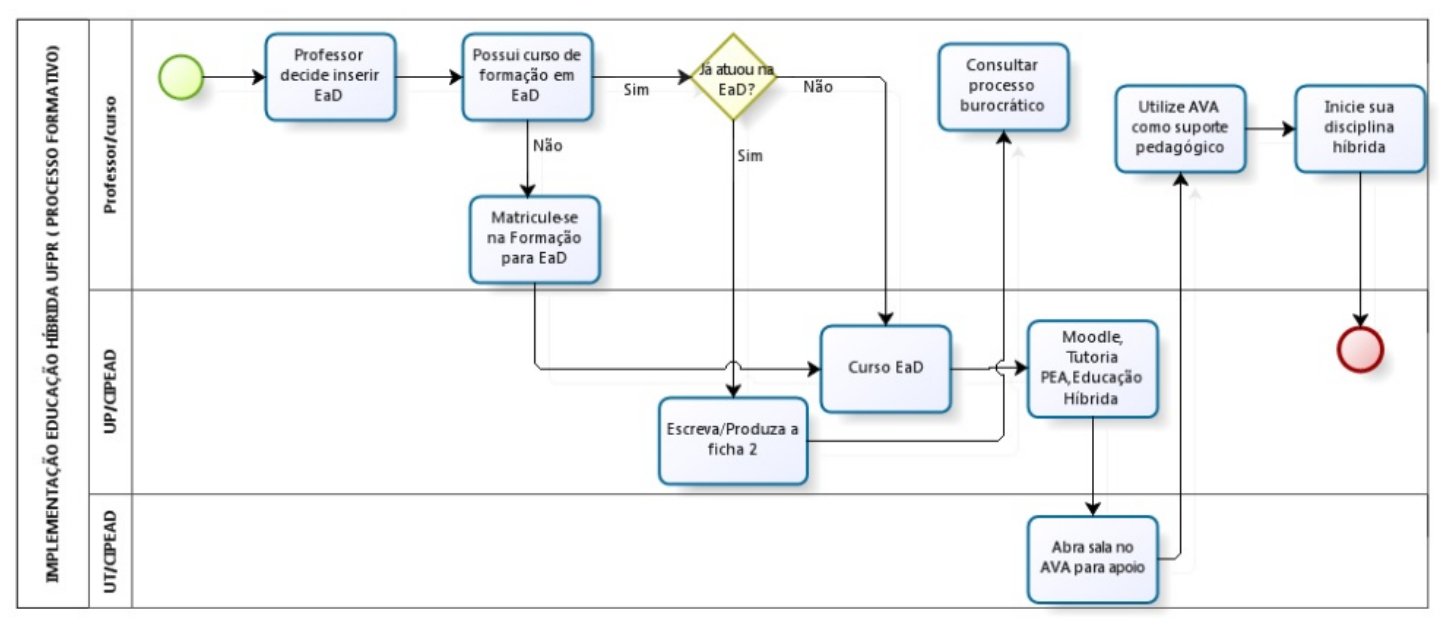

Fonte: UFPR. Cursos de Formação (s/d).

A coleta de dados ocorreu a partir dos artefatos (LANKSHEAR; KNOBEL, 2008) que compuseram e compõem o projeto UFPR HÍBRIDA nos anos de 2017 e 2018, promovendo a "reflexão [...] sobre as próprias experiências" (LANKSHEAR; KNOBEL, 2008, p. 18). Foram utilizados como instrumentos de coleta de dados os seguintes artefatos: planilhas de registro de cursos com adesão à UFPR HÍBRIDA, site do projeto e registros jornalísticos das experiências do projeto (2018) com os cursos de "Educação Híbrida" e "Vivências formativas para a educação híbrida". Os artefatos "surgem em muitas formas diferentes [...] e ajudam a construir a contextualização dos dados para um estudo" (LANKSHEAR; KNOBEL, 2008, p. 41).

\section{Apresentação e discussão dos resultados}

Desde 2010 houve um expressivo crescimento das ofertas de cursos e disciplinas híbridas. Atualmente estão registradas 296 disciplinas híbridas ou totalmente a distância de 32 cursos da graduação presencial. Para divulgar as ações do projeto foi criado o site UFPR HÍBRIDA localizado no endereço: http://www.cipead.ufpr.br/portal/ufpr-hibridal. O site representa o espaço online para consulta de informações sobre o projeto e a concepção da educação híbrida. Entre as informações do site há um quadro de ferramentas digitais que podem ser utilizadas para várias finalidades: avaliação, criação de nuvens de palavras e mapas mentais, apresentação, colaboração dentre outras. A página também é uma ferramenta que contribui com a divulgação das ações sobre a Educação Híbrida na UFPR, sendo comunicadas as ofertas de cursos a distância e das vivências formativas.

Visando a capacitação de professores e colaboradores para a oferta de disciplinas e 
cursos com parcialidade a distância criou-se o curso de Educação Híbrida que é uma das ações que compõem o projeto UFPR HÍBRIDA. Integra espaços de aprendizagem online e presencial, com apoio do Moodle UFPR, ambiente virtual de aprendizagem oficial da instituição (www.ava.ufpr.br), aos processos formativos realizados nas dependências físicas da instituição. Está estruturado em três módulos que acontecem na modalidade semipresencial possuindo dois encontros presenciais. Tem a duração de 45h distribuídas em 7 semanas.

Possui objetivos de capacitar o cursista a descrever e caracterizar o ensino híbrido; reconhecer e sistematizar as possibilidades de implantação do ensino híbrido na UFPR; planejar uma disciplina/curso utilizando as orientações da resolução n. 72/10 - CEPE e organizar estratégias didáticas utilizando diversos recursos e dispositivos para a consecução da Educação Híbrida.

Os encontros visam a experimentação do modelo de estação por rotações (HORN; STAKER, 2015; BACICH; TANZI NETO; TREVISANI, 2015) e contemplam atividades colaborativas e individuais com o apoio de diferentes tecnologias digitais que incluem 0 uso de aplicativos de avaliação (Plickers, Kahoot, Mentimeter, Google Forms), ferramentas de colaboração e construção de mapas mentais (Google docs, GoconQR, Freemind, Padlet), Plataformas de MOOCs, ferramentas de apresentação (Google apresentação, Emaze), óculos de realidade virtual e aplicativos de realidade aumentada.

A turma 2018 contará com acessibilidade para a comunidade surda. O material textual foi traduzido para LIBRAS e o AVA contará com a mediação de um tutor e um intérprete de libras.

Outra ação implementada em 2018 foram as vivências formativas para a educação híbrida. Sua concepção teve origem após o curso de educação híbrida e possuem o objetivo de proporcionar a experimentação de práticas educacionais inovadoras. As vivências foram, e continuam sendo ofertadas, para a comunidade acadêmica ouvinte e surda da UFPR no ano de 2018.

Um dos participantes das vivências é surdo e afirma que "a educação híbrida foi algo que me abriu os horizontes, pude pensar em novas estratégias metodológicas para que os alunos surdos também se desenvolvam" (UFPR, 2018).

No primeiro semestre foram ofertadas 5 (cinco) vivências, a saber: Moodle básico, Educação híbrida na prática, Design thinking: soluções inovadoras, Produção de videoaulas e Tecnologias educacionais. Mais do que palestras as atividades foram 
organizadas para propiciar a experimentação de cada um desses temas. Mais de 32 pessoas estiveram presentes nos cinco encontros e avaliaram as atividades como oportunidade de reflexão, colaboração e planejamento de práticas inovadoras.

Figura 3 - Banner de divulgação da oficina de Produção de VideoAulas, uma das Vivências Formativas para a Educação Híbrida.

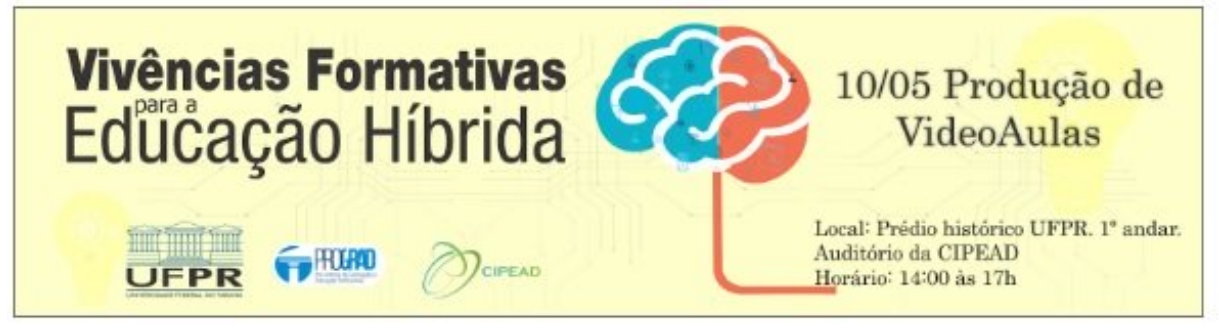

Fonte: UFPR (s/d).

Figura 4 - Comunidade surda acompanha a vivência formativa para a Educação Híbrida com auxílio de intérprete de libras.

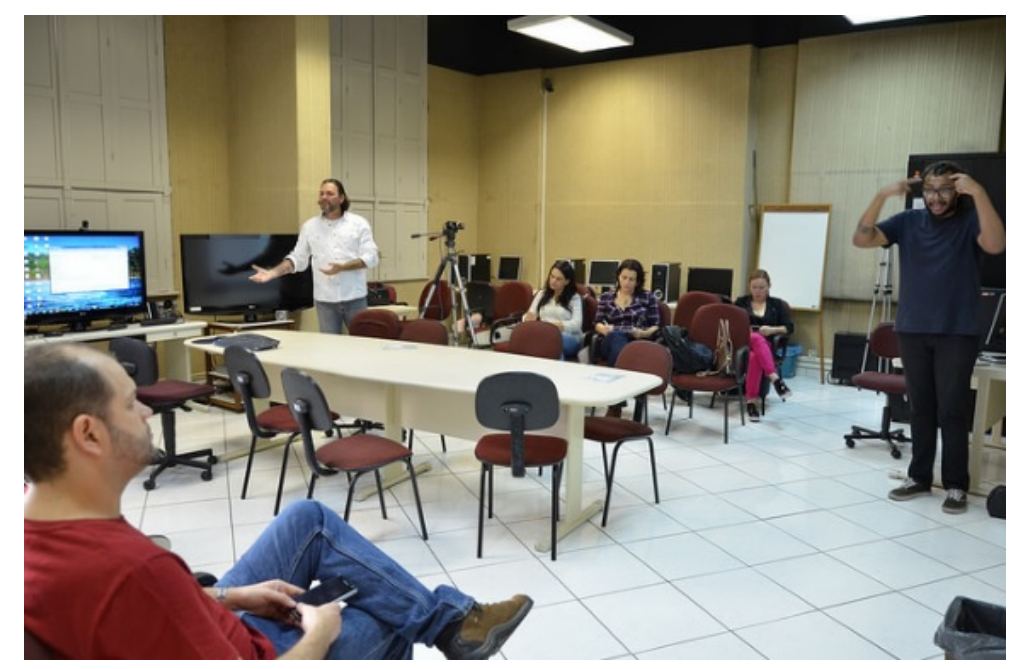

Fonte: UFPR (2018).

\section{Considerações finais:}

As ações da UFPR HÍBRIDA caminham para a uma compreensão da Educação Híbrida na comunidade universitária e os resultados apontam que essa concepção está sendo construída e praticada. O projeto UFPR HÍBRIDA tem avançado ao continuar os esforços formativos com abordagens cada vez mais compartilhadas, abertas e acessíveis, para que o processo seja construído em conjunto e não para os outros, ou seja, incorporando princípios da cocriação, e dessa forma tem ajudado a criar parcerias 
e uma rede de colaboração.

Por vezes o projeto demanda apoio de profissionais em áreas específicas ou mesmo, necessita de infraestrutura e recursos tecnológicos próprios, o que indica também a importância de financiamento e de políticas para a educação superior favoráveis às práticas híbridas. Além disso, há lacunas e aspectos que podem ser aprimorados para que se fortaleça a Educação Híbrida na UFPR, por exemplo em relação à personalização do ensino, pois uma ampliação e agilidade no sistema de ensino e de aprendizagem depende de uma plataforma adaptativa que provavelmente se baseia em inteligência artificial. E outro aspecto que se faz necessário para a UFPR HÍBRIDA é o desenvolvimento de instrumentos que comparem os resultados formativos oriundos da Educação Híbrida com o de outras práticas.

\section{Referências}

BACICH, L. Ensino Híbrido: personalização e tecnologia na educação. (Apresentação). s/d. Disponível em $<$ http://www2.camara.leg.br/atividade-legislativa/comissoes/comissoes-permanentes/ce/ documentos-1/apresentacoes-de-audiencias-e-seminarios/apresentacao-lilianbacich/view> Acesso em: 17. maio 2018.

BACICH, L.; TANZI NETO, A.; TREVISANI, F. M. (Org.). Ensino híbrido: personalização e tecnologia na educação. Porto Alegre: Penso, 2015.

CHRISTENSEN, C. M; HORN M. B; STAKER, H. Ensino híbrido: uma inovação disruptiva? Uma introdução à teoria dos híbridos. 2013. Disponível em $<$ https://www.pucpr.br/wp-content/uploads/2017/10/ensino-hibrido uma-inovacaodisruptiva.pdf> Acesso em: 17. maio 2018.

GOMES, N. F.; SERRANO, M. J. Tecnologias e Modelos de Aprendizagem Emergentes no Ensino Superior: propostas e aplicações de inovações. Teoría de la Educación. Educación y Cultura en la Sociedad de la Información, 2014, 15 (Dezembro). Disponível em <http://www.redalyc.org/html/2010/201032973007/> Acesso em: 16. maio 2018.

HORN, B. M.; STAKER, H. Blended: usando a inovação disruptiva para aprimorar a educação. Porto Alegre: Penso, 2015. Trad. Maria Cristina Gularte Monteiro.

JOHNSON, L., ADAMS BECKER, S., CUMMINS, M., ESTRADA, V., FREEMAN, A., 
HALL, C. (2016). NMC Horizon Report: 2016 Higher Education Edition. Austin, Texas: The New Media Consortium. Disponível em: $<$ http://cdn.nmc.org/media/2016-nmc-horizon-report-he-EN.pdf >. Acesso em: 10. abr. 2018.

LANKSHEAR, C.; KNOBEL, M. Pesquisa pedagógica: do projeto à implementação. Porto Alegre: Artmed, 2008.

MACHADO, N. S.; LUPEPSO, M.; JUNGBLUTH, A. Educação Híbrida. Guia de Leitura do curso Educação Híbrida. Edição e Revisão: Maria Josele Bucco Coelho. CIPEAD Coordenação de Integração de Políticas de Educação a Distância. Universidade Federal do Paraná, 2017.

PERES, P.; PIMENTA, P. Teorias e práticas de b-learning. Lisboa: Edições Sílabo Ltda., 2011.

TORI, R. Cursos híbridos ou blended learning. In: FORMIGA, M e LITTO, F. Educação a Distância: o estado da arte. São Paulo: Pearson Education, 2009. Disponível em $<$

http://www.abed.org.br/site/pt/midiateca/bibliografia/527/2004/12/educacao_a_distancia_ - o_estado_da_arte> Acesso em: 18. maio 2018.

UFPR. Conselho de Ensino, Pesquisa e Extensão - CEPE. Resolução n. 72/10. Regulamenta a oferta de disciplinas na modalidade a distância nos cursos de graduação e educação profissional e tecnológica presenciais da Universidade Federal do Paraná, 2010. Disponível em: $<$ http://www.cipead.ufpr.br/portal/ufpr-hibrida/wpcontent/uploads/sites/3/2017/08/cepe7210.pdf> Acesso em: 22. abr. 2018.

CIPEAD. UFPR HíBRIDA. s/d. Disponível em: $<$ http://www.cipead.ufpr.br/portal/ufpr-hibrida/> Acesso em: 10. maio. 2018.

CIPEAD. UFPR HÍBRIDA. Cursos de formação. s/d. Disponível em: $<$ http://www.cipead.ufpr.br/portal/ufpr-hibrida/cursos-de-formacao/> Acesso em: 10. maio. 2018.

Portal UFPR. Programa UFPR Híbrida oferece vivências formativas com acessibilidade para a comunidade surda. 2018. Disponível em: $<$ http://www.ufpr.br/portalufpr/noticias/programa-ufpr-hibrida-oferece-vivencias- 
formativas-com-acessibilidade-para-a-comunidade-surda/> Acesso em: 14. maio. 2018. 